\title{
EQUIVALENT FORMS FOR A POSET TO BE MODULAR POSET
}

\author{
P. Sundarayya And T. Ravi Kishore \\ Department of Mathematics \\ GITAM (deemed to be University), Visakhapatnam \\ Andhra Pradesh, India - 530003 \\ e-mail: psundarayya@gmail.com \\ kishore.tangi@gmail.com
}

\begin{abstract}
The notion of modular and distributive posets which generalize the corresponding notions from the lattice theory are introduced by J. Larmerova and J. Rachnek. Later some extended results of uniquely complemented lattice are derived to uniquely complemented posets. Now, in this paper, some equivalent conditions for a poset to be modular poset are given.
\end{abstract}

Keywords: poset, lattice, modular poset.

2010 Mathematics Subject Classification: 06A06, 06A11.

\section{REFERENCES}

[1] G. Brikhoff, Lattice Theory, American Mathematical Society (Coloquium Publications American Mathematical Society, 1961).

[2] G. Gratzer, General Lattice Theory (Birkhauser, New York, 1998).

[3] J. Larmerova and J. Rachunek, Translations of distributive and modular ordered sets, Acta Univ. Palacki Olomonc 91 (1988) 13-23.

[4] S. Burris and H.P. Sankappanavar, A Course in Universal Algebra (Springer, 1981).

[5] B.N. Waphare and V.V. Joshi, On uniquely complemented posets, Order 22 (2005) 11-20. doi:10.1007//s11083-005-9002-0

Received 2 March 2020

Revised 3 April 2020

Accepted 8 April 2020 